\title{
Utility-Interconnected Photovoltaic Systems: Evaluating the Rationale for the Utility-Accessible External Disconnect Switch
}

\section{Michael H. Coddington, Senior Engineer}

National Renewable Energy Laboratory • Golden, CO 80401

\section{External Disconnect Discussion}

- Utility-Accessible, Visible-Break, Lockable AC Switch (PV Systems)

- Typically Required by Utilities if they are given the Decision

- Considered Unnecessary Expense by System Integrators and Customers

- The AC EDS is Rarely Used (if ever)

\section{Utility Line Work Practices}

- New Construction

- Test and Ground - Work "Cold"

- Electric System Trouble

- Assume Energized - Work "Hot"

- Timely Restoration of Outages

- Safe and Fast Outage

Restoration Critical

\section{Why Utilities Ask for UA EDS}

- Protection of Line Workers

- In the Event of a Feeder Outage

- To Protect Line Equipment

- Isolation of Customer Problems

- Isolation of All Power Sources

Who Has Eliminated the EDS Requirement?

- SMUD

- PG\&E

- Arkansas, Florida, New Jersey
Prime Focal Points for Utilities

- Safety (NESC, OSHA)

- National Electrical Safety Code

- Occupational Safety and Health

Administration

- Reliability (S.A.I.D.I. - S.A.I.F.I. etc.)

- System Average Interruption Duration Index

- System Average Interruption Frequency Index

- Cost (Capital and Expense)

- Capital Investments (Return On Investment)

- Expenses (Some Expense Not Recoverable)

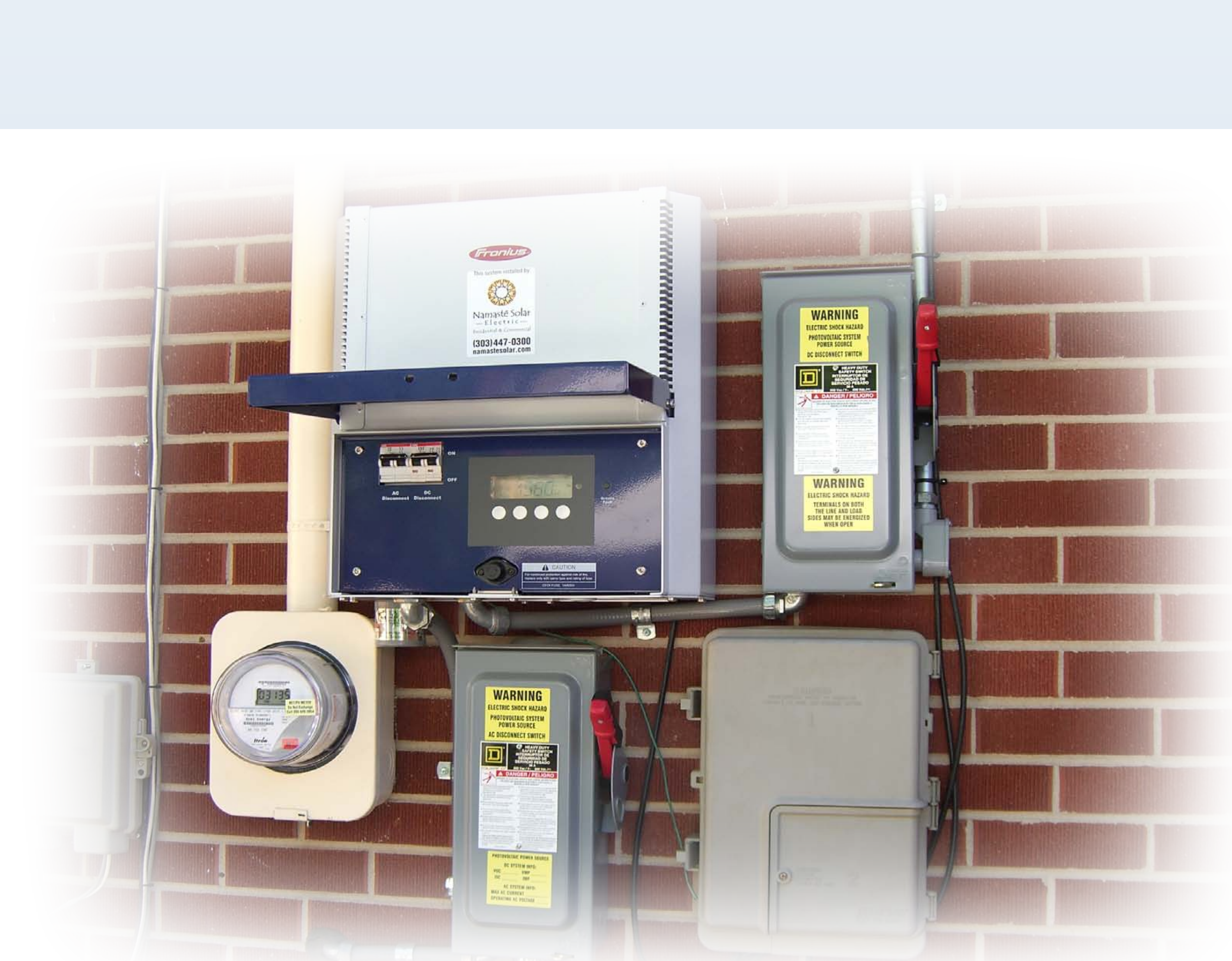

\section{Critical PV System Standards}

- IEEE 1547

- Cornerstone Standard Interconnection

- Addresses Both Sides of Utility Meter

- UL 1741

- Sets Standards for Grid Connection

- Units Disconnect from Grid with Voltage/Frequency Variations

- National Electrical Code

- The "Law" in Most Jurisdictions beyond meter

Utility Accessible EDS - Redundant

- PV Systems Have Many Disconnects

- Utilities Tend to Ignore EDS

- PG\&E and SMUD Don't Require EDS

- Some PUCs Have Eliminated EDS Requirements or Defer to Utilities

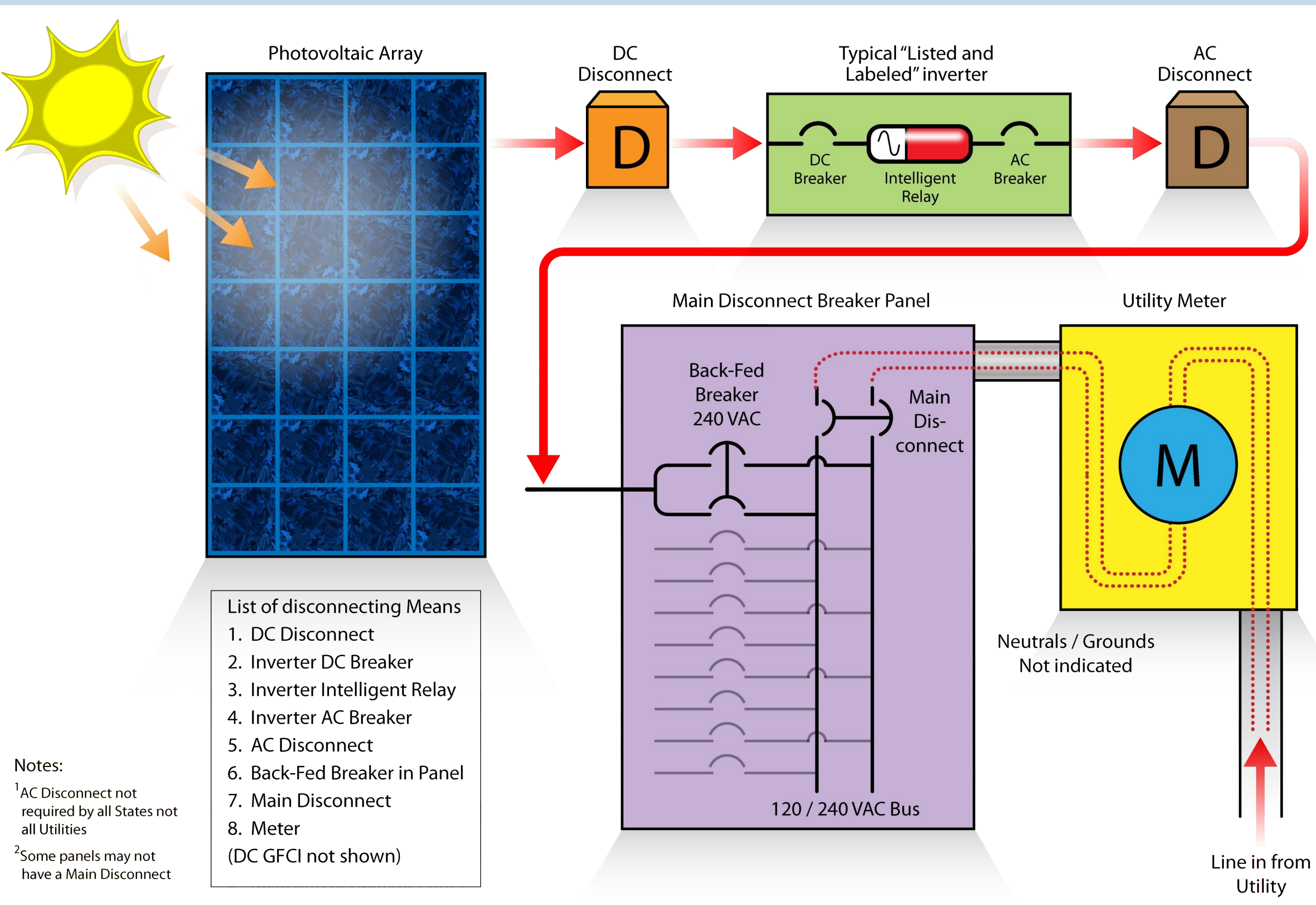

